\title{
Features of the value-oriented sphere of managers of enterprises with market and hierarchical organizational culture
}

\author{
E. V. Markova ${ }^{1}$
}

${ }^{1}$ P. G. Demidov Yaroslavl State University, 14 Sovetskaya str., Yaroslavl 150003, Russian Federation

DOI: $10.18255 / 1996-5648-2021-1-120-127$

Research article

Full text in Russian

Value orientations of a manager are a factor in the formation and development of organizational culture. In a modern economy, an organization whose culture includesthevalue of a marketing approachwillbeeffective.Knowledgeof thevalue orientations of managers who introduce market culture in organizations will allow organizational psychologists to solve the problem of optimizing culture. The article presents the results of an empirical study of differences in the level of expression of value orientations among managers who implement their professional activities in different organizational cultures. Emphasis is placed on the list of those structural features of the system of individual value orientations of managers that will allow predicting the development of market organizational culture.

Keywords: value orientations; organizational culture; manager; market organizational culture; hierarchical organizational culture; reliability of differences

\section{INFORMATION ABOUT AUTHORS}

Markova Elena V. | E-mail:vark_ev@mail.ru

Cand. Sc. (Psychology), Associate Professor 


\title{
Особенности ценностно-ориентационной сореры руководителей предприятий с рыночной и иерархической организационной культурой
}

\author{
Е. В. Маркова ${ }^{1}$
}

${ }_{1}^{1}$ Ярославский государственный университет им. П. Г. Демидова, ул. Советская, 14, Ярославль, 150003, Российская Федерация

DOI: $10.18255 / 1996-5648-2021-1-120-127$

УДК 159.9

Научная статья

Полный текст на русском языке

Ценностные ориентации руководителя - фрактор формирования и развития организационной культуры. В условиях современной экономики эффективной будет та организация, культура которой включает ценность маркетингового подхода. Знание ценностных ориентаций руководителей, внедряющих в организациях рыночную культуру, позволит организационным психологам решить задачу оптимизации культуры. В статье приводятся результаты эмпирического исследования различий в уровне выраженности ценностных ориентаций у руководителей, реализующих свою профессиональную деятельность в разных организационных культурах. Сделан акцент на перечне тех структурных особенностей системы индивидуальных ценностных ориентаций руководителей, которые позволят прогнозировать развитие рыночной оргкультуры.

Ключевые слова: ценностные ориентации; организационная культура; руководитель; рыночная организационная культура; иерархическая организационная культура; достоверность различий

\section{ИНФОРМАЦИЯ ОБ АВТОРАХ}

\author{
Маркова Елена Владимировна | E-mail:vark_ev@mail.ru \\ Кандидат психологических наук, доцент
}

Рыночная и иерархическая организационная культура обладают определенными сходствами и различиям. Объединяет эти культуры наличие требований, норм, правил, которые должны соблюдаться сотрудниками. Упорядоченность обеих культур позволяет им обеспечивать адаптацию организации к условиям неопределенности. Ключевое различие между этими культурами заключается в том, что рыночная культура предполагает клиенториентированное поведение персонала, а ие- 
Маркова Е. В.

рархическая - допускает ориентацию на внутренние процессы в жизни организации. Очевидно, что именно клиенториентированность обеспечивает организации конкурентоспособность и что, даже если по роду деятельности структура предприятия иерархична, рыночные ценности будут способствовать развитию бизнеса. Становится актуальным обращение к организационной культуре как к средству изменения бизнес-культуры, формирования новых ценностных ориентиров и воспитания института «грамотного собственничества».

Основу любой организационной культуры составляют ценности и нормы поведения, поддерживающие воспроизводство господствующих ценностей организации. Ценности обеспечивают сохранение целостности социальной системы (организации), в ценностях выражается особая значимость определённых материальных и духовных благ для существования и развития системы. С точки зрения управления персоналом организации важны как ценности-цели, отражающие стратегические цели существования организации, так и ценности-средства, т. е. те ценные для данной организации качества персонала (например, дисциплинированность, честность, инициативность) и характеристики внутренней среды (например, командный дух), которые позволяют достигнуть ценности-цели.

Иерархическая организационная культура - формализованное и структурированное место работы. Часто ее называют бюрократическим типом организационной культуры. В такой организации тем, что делают люди, управляют процедуры. Лидеры гордятся, что они рационально мыслящие координаторы и организаторы. Ценится поддержание плавного хода деятельности организации, которую объединяют формальные правила и официальная политика. Управление работниками предполагает озабоченность гарантией занятости и обеспечением долгосрочной предсказуемости поведения сотрудников.

Рыночная культура доминирует в организациях, ориентированных на результаты. Ее главная забота - выполнение поставленной задачи. Люди целеустремленны и соперничают между собой. Лидеры - твердые руководители и суровые конкуренты. Они непоколебимы и требовательны. Организацию связывает воедино акцент на стремлении побеждать. Репутация и успех составляют предмет общего радения. Стиль организации - жестко проводимая линия на конкурентоспособность.

Цель эмпирического исследования: выявление ценностных ориентаций руководителей в различных организационных культурах.

Объект исследования: ценностные ориентации.

Предмет исследования: ценностные ориентации руководителей, реализующих свою профессиональную деятельность в условиях различных организационных культур.

Гипотеза исследования состоит в предположении, что руководители в условиях рыночной организационной культуры в большей степени 
Особенности ценностно-ориентационной сферы руководителей...

ориентированы на ценность материального благополучия и саморазвития, а руководители в условиях иерархической организационной культуры на уверенность в завтрашнем дне.

Базой исследования являются организации г. Ярославля: АО «ЯЗТА», АО «ЯЗДА»; в коммерческих структурах: магазины «Спектр» и "Автозапчасти», «Лефрко-банк», компьютерные фрирмы «Эском», «Тензор», «Скан», $\mathrm{AO} \ll \mathrm{TИИР».}$

Выборка испытуемых состояла из 54 человек, из них 39 мужчин и 15 женщин. Возраст испытуемых - от 26 до 58 лет. Стаж профессиональной деятельности - от 2 до 28 лет.

В соответствии с целью и гипотезой исследования в качестве эмпирических методик использовались:

1. Методика «Опросник терминальных ценностей» (ОТеЦ) (И. Г. Сенин) [1].

2. Методика диагностики корпоративной культуры Камерона и Куинна (методика ОСАI) [2].

Ръночная организационная кулътура

Проанализируем результаты, полученные на выборке руководителей предприятий с рыночной организационной культурой (табл. 1).

Средние значения диагностических показателей Таблица 1

\section{в группе руководителей предприятий с рыночной оргкультурой}

\begin{tabular}{|l|c|c|}
\hline \multicolumn{1}{|c|}{ Диагностические показатели } & $\begin{array}{c}\text { Среднее } \\
\text { значение }\end{array}$ & $\begin{array}{c}\text { Стандартное } \\
\text { отклонение }\end{array}$ \\
\hline Собственный престиж & 44 & 7,6 \\
\hline Высокое материальное положение & 46 & 7,7 \\
\hline Креативность & 39 & 7,3 \\
\hline Активные социальные контакты & 38 & 5,6 \\
\hline Развитие себя & 33,6 & 5,9 \\
\hline Достижения & 43 & 6,5 \\
\hline Духовное удовлетворение & 27 & 5,6 \\
\hline Сохранение собственной индивидуальности & 31 & 6,3 \\
\hline Сорера профессиональной жизни & 66,6 & 9,7 \\
\hline Сфрера обучения и образования & 65 & 10,5 \\
\hline Сфрера семейной жизни & 51,5 & 6,4 \\
\hline Сорера общественной жизни & 50 & 11 \\
\hline Сфрера увлечений & 50,3 & 11,8 \\
\hline
\end{tabular}

Высокий уровень значимости для руководителей данной группы имеет: собственный престиж, высокое материальное положение, достижения, 
Маркова Е. В.

а также такие жизненные сореры, как профессиональная жизнь и обучение и образование. Выявленные особенности вполне логично сочетаются с рыночным типом организационной культуры. Стремление к собственному престижу, достижениям и высокому материальному положению находит свое удовлетворение в конкурентной борьбе, в стремлении к победе, в движении к поставленным целям.

Именно стремление к достижениям является одной из основных характеристик рыночной оргкультуры. Идентичные ценности у руководителя предприятия позволяют ему эффективно выполнять свои задачи. Значимость для руководителей этой группы профессиональной жизни и обучения также подтверждают этот вывод. В современных, быстро меняющихся условиях регулярное обучение и образование являются необходимым условием успеха. Постоянное повышение своей компетентности позволяет «идти в ногу со временем», своевременно реагировать на изменения и направлять деятельность организации в нужное русло.

Результаты исследования ценностных ориентаций в группе руководителей предприятий с иерархической оргкультурой представлены в табл. 2.

Средние значения диагностических показателей Таблица 2

\section{в группе руководителей предприятий с иерархической оргкультурой}

\begin{tabular}{|l|c|c|}
\hline \multicolumn{1}{|c|}{ Диагностические показатели } & $\begin{array}{c}\text { Среднее } \\
\text { значение }\end{array}$ & $\begin{array}{c}\text { Стандартное } \\
\text { отклонение }\end{array}$ \\
\hline Собственный престиж & 41 & 6,6 \\
\hline Высокое материальное положение & 35 & 7,4 \\
\hline Креативность & 15 & 7,3 \\
\hline Активные социальные контакты & 20 & 6,6 \\
\hline Развитие себя & 30,6 & 5,6 \\
\hline Достижения & 25,4 & 6,5 \\
\hline Духовное удовлетворение & 27 & 5,6 \\
\hline Сохранение собственной индивидуальности & 12 & 6,3 \\
\hline Сфрера профессиональной жизни & 65,6 & 10,5 \\
\hline Сфрера обучения и образования & 40,4 & 9,7 \\
\hline Сфрера семейной жизни & 70,3 & 7,4 \\
\hline Сорера общественной жизни & 44 & 11,6 \\
\hline Сфрера увлечений & 39,2 & 11,8 \\
\hline
\end{tabular}

Как показывают результаты, наибольшее значение для руководителей этой группы имеют: собственный престиж, срера профессиональной жизни, сорера семейной жизни. Низкие значения зафиксированы по таким ценностям, как креативность, активные социальные контакты, сохранение 
Особенности ценностно-ориентационной сферы руководителей...

собственной индивидуальности. Для руководителей наибольшее значение имеет собственный престиж. При этом, вероятно, престиж достигается прежде всего за счет четкого исполнения своих обязанностей, построения формализованной системы работы, жесткого контроля за подчиненными. Другими словами, престиж понимается преимущественно как фрормальная характеристика: социальный статус, занимаемое положение, производственные показатели предприятия и т. п. Этот вывод подтверждается низкой значимостью креативности, социальных контактов и сохранения собственной индивидуальности.

Для определения различий в системе ценностей руководителей иерархической и рыночной организационных культур нами были использованы статистические математические методы подсчета обнаружения достоверности различий. Был использован $\mathrm{t}$ - критерий Стьюдента.

Результаты проверки достоверности различий между выборками руководителей, работающих в рыночной и иерархической организационных культурах, по t - критерию Стьюдента следующие:

А) достоверность различий на уровне значимости 0,95 подтверждена для таких составляющих ценностно-ориентационной сферы личности как:

- высокое материальное положение;

- креативность;

- достижения;

- сохранение собственной индивидуальности.

Б) достоверность различий на уровне значимости 0,99 выявлена для таких терминальных ценностей как:

- активные социальные контакты;

- сорера образования и обучения;

- сорера семейной жизни.

Значимые различия между выборкой руководителей в условиях рыночной оргкультуры и руководителей в условиях иерархической оргкультуры достоверны для семи из тринадцати исследуемых устойчивых терминальных и инструментальных ценностей.

Анализируя средние показатели по критериям, имеющим достоверность различий, можно сказать, что наибольшие значения наблюдаются у выборки руководителей в условиях рыночной оргкультуры. Исключение составляет только сорера семейной жизни, значимость которой выше у руководителей в условиях иерархической оргкультуры.

Далее на основе матриц интеркорреляций для каждой группы были построены графические структуры связей - структурограммы. Для более наглядной демонстрации связей внутри структурограммы использовался такой графический метод отражения связей между переменными, как дендрограмма.

Выше были описаны аналитические различия, позволяющие сделать заключение о сравнительной специфике отдельных ценностей руководи- 
Маркова Е. В.

телей в условиях рыночной и иерархической организационной культуры. Встает вопрос: наблюдаются ли эти различия на структурном уровне? Чтобы ответить на него, необходимо сравнить интеркорреляционные матрицы и структурограммы системы ценностей у руководителей выделенных групп. Для дополнительной информации при анализе структурограмм использовался «индекс организованности структур» (ИОС) [3] и определение гомогенности - гетерогенности структур экспресс-методом $\chi 2$. Наибольший структурный вес имеют следующие ценностные ориентации личности: сфрера образования и обучения (СОО); сфрера увлечений (СУ); сорера профрессиональной жизни (СПЖ⿱ $)$; сохранение собственной индивидуальности (ССИ); развитие себя (РС); активные социальные контакты (АКС).

Сравнение весовых структур двух выборок позволяет сделать вывод о большей организованности структуры руководителей организаций с рыночной организационной культурой. В численном выражении структурированность отражкает «индекс организованности структур» (ИОC).

ИОС руководителей иерарахических (бюрократических) организационных культур - 185; ИОС руководителей рыночных организационных культур - 217 (табл. 3).

Таблица 3

Весовые коэффициенты параметров ценностной сферы

\begin{tabular}{|l|c|c|}
\hline \multicolumn{1}{|c|}{ Ценности } & $\begin{array}{c}\text { Руководители } \\
\text { в условиях } \\
\text { иерархической } \\
\text { оргкультуры }\end{array}$ & $\begin{array}{c}\text { Руководители } \\
\text { в условиях } \\
\text { рыночной } \\
\text { оргкультуры }\end{array}$ \\
\hline Собственный престиж & 11 & 10 \\
\hline Сфера увлечений & 9 & 11 \\
\hline Сфера общественной жизни & 6 & 10 \\
\hline Сфера семейной жизни & 6 & 4 \\
\hline Сфера обучения и образования & 8 & 11 \\
\hline Сфера профессиональной жизни & 10 & 12 \\
\hline Сохранение собственной & 10 & 8 \\
\hline индивидуальности & 6 & 11 \\
\hline Духовное удовлетворение & 2 & 11 \\
\hline Достижения & 9 & 11 \\
\hline Развитие себя & 10 & 10 \\
\hline Активные социальные контакты & 8 & 9 \\
\hline Креативность & 5 & 12 \\
\hline Высокое материальное положение & & \\
\hline
\end{tabular}


Особенности ценностно-ориентационной сферы руководителей...

По разнице весов можно дополнительно выделить такую терминальную ценность для руководителей в условиях рыночной оргкультуры, как «высокое материальное положение», а также личностный мотив "собственный престиж», который наблюдается у руководителей обеих выборок.

Обобщая полученные результаты, можно сделать следующие выводы:

1. Наиболее важные различия между руководителями в условиях рыночной и иерархической оргкультуры обнаружились по таким показателям, как сохранение собственной индивидуальности; активные социальные контакты; сфрера обучения и образования; сфера увлечений; сорера общественной жизни. Поэтому мы можем предполагать, что руководители, работающие в условиях рыночной оргкультуры, обладают специфрическими ценностными характеристиками по сравнению с бюрократическими руководителями;

2. Руководители в условиях рыночной оргкультуры, ориентируясь на внутренние возможности, активно ищут выход из сложившейся критической ситуации, пытаясь найти новые источники доходов, используя новые виды хозяйственной деятельности. Представители данной структуры характеризуются не только позитивным отношением к форме собственности, видам экономической деятельности, готовностью работать в новых условиях, но и достаточно успешной самореализацией. Стремление к повышению профессионального и социального статуса, освоение новых сорер деятельности, высокая социальная мобильность и инновационность являются отличительными чертами предпринимателя;

3. Руководителям в условиях иерархической оргкультуры свойственно придерживаться традиционных видов ведения экономической и хозяйственной деятельности. Они не проявляют высокой психологической готовности к самореализации, характеризуются сочетанием негативного отношения к новым фрормам поведения и предлагают пассивно выжидающую позицию в отношении происходящих изменений. Причиной этого может служить низкий уровень мотивации и низкая самооценка собственных возможностей в сорере деятельности.

\section{Ссылки}

1. СенинИ.Г.Опросниктерминальныхценностей.Ярославль:Психодиагностика, 1991. 19 c.

2. Камерон К., Куинн Р. Диагностика и изменение организационной культуры. СПб.: Питер, 2001. 214c.

3. Карпов А. В. Психология принятия управленческих решений. М.: Юристъ, 1998. 440 c. 